\title{
LITERATURA ANARQUISTA Y ANARQUISMO LITERARIO
}

El movimiento anarquista que se difunde en España a raíz de la Revolución de 1868 desarrolla una literatura militante que populariza los principios doctrinales del internacionalismo. Desnuda de pretensiones artísticas, esa literatura atenúa la aridez teórica y facilita la vulgarización de complicados conceptos revolucionarios.

No es raro encontrar, entre reseñas de congresos obreros y noticias sobre el desarrollo de la Federación española, poesías y prosas firmadas con iniciales y nombres desconocidos, o por "un trabajador", "un jornalero", "un explotado" salidos de la masa de lectores anarquistas. En estas composiciones, el "obrero consciente" suele dirigirse a sus compañeros para explicarles problemas ideológicos de difícil comprensión o para insistir en la necesidad de ingresar en el movimiento, de leer la prensa obrera, de educarse:

Instruirse, compañeros,

aplicarse a la lectura;

seamos nuevas criaturas,

que son fines verdaderos ${ }^{1}$.

La literatura militante no es, desde luego, patrimonio exclusivo del movimiento anarquista. Otros grupos radicales desarrollaban también un arte social que exponía los temas y preocupaciones más candentes. Republicanos y federales llevaban a la literatura sus ataques contra las quintas, la monarquía, los consumos:

Fuera consumos y quintas,

que no queremos pagar.

Lo que ahora deseamos:

República Federal?

Pero mientras los partidos políticos pensaban exclusivamente en

1. La Autonomia, Sevilla, 29.VII.1885. p. 3.

- Cit. por José Termes Ardévol, El movimiento obrero en España. La Primera Internacional (1864-1S51), Barcelona, 1965, pp. 27-28. 
cambios que transformasen las estructuras de poder, el movimiento libertario perseguía una revolución social y económica que destruyera el Estado y creara una sociedad sin gobierno ni clases. Por otra parte, si las manifestaciones literarias demócratas y republicanas acudían a temas concretos -acontecimientos y asuntos de actualidad-, los internacionalistas recalcaban, en cambio, la lucha de clases, el colectivismo, la federación y la unión de comunas libres y de obreros -en otras palabras, los principios básicos del anarquismo.

En los lustros que siguen al establecimiento de la Federación Regional Española de la Asociación Internacional de Trabajadores, la literatura ácrata florece y se multiplica gracias a la constante expansión de la prensa obrera peninsular. La posibilidad de publicar en cualquier periódico del movimiento, y no exclusivamente en órganos de carácter artístico, facilita de manera considerable estas actividades. La preocupación por el contenido ideológico y no por los logros estéticos anima también al lector militante a contribuir a este desarrollo con los modestos partos de su musa.

Durante la última década del siglo se complica significativamente el panorama intelectual y artístico de toda Europa. Escritores cultos, a menudo de origen aristocrático o burgués, manifiestan creciente simpatía por el anarquismo, en el cual ven un movimiento rebelde, individualista e innovador. El intelectual déclassé, insatisfecho con la sociedad que lo rodea, repudia como los anarquistas las instituciones estáticas y la atmósfera rancia que se respira. La España oficial de fin de siglo, sofocada entre la Restauración y: el Desastre, es atacada no sólo por las masas oprimidas, sino también por los artistas, ansiosos de horizontes más amplios.

Pero si intelectuales y obreros compartían los mismos afanes; esto no equivalía a una estrecha identificación ideológica. Para los escritores, anarquía era sinónimo de total libertad de formas y esti$\operatorname{los}^{3}$ : Más aún, los aspectos destructores del anarquismo representaban un gran atractivo para quienes estaban comprometidos con un rechazo total del pasado y una radical renovación estética. La crí. tica ha señalado cómo los escritores franceses se sintieron fascinados por los rasgos destructivos del terrorismo anarquista: Ravachol, Henry, Vaillant eran los héroes de moda en los medios intelectuales de Francia en los años de l'affaire Dreyfus*. Algo semejante podría,

3 Cf. Rubén Darío, España contemporánea (t. 21 de sus Obras completas, Madrid, s. a.), "crónica" del 28.XI.1899, pp. 280-281, y EDUardo SANz Y EscarTín, Federico Nietzsche y el anarquimo intelectual, Madrid, 1898, pp. 44-45 y. 51-52. Pío Baroja, en sus Memorias (Obras completas, t. 6, Madrid, 1948, p. 568), recuerda que la "equiparación de la anarquía con la literatura [que hace Enrique Cornuty en un mitin del teatro Barbieri] no se podia considerar disparatada, sino más bien certera, porque la anarquía de ese tiempo era cosa más literaria que política".

4. Cf. Pierre Aubery, "L'anarchisme des littérateurs au temps du symbo- 
sin duda, establecerse para España si se investigara el impacto de la "propaganda por el hecho" -el tiranicidio, el atentado terrorista- sobre los intelectuales. Fermín Salvochea, Paulino Pallas, Angiolillo tienen algo de héroes románticos en un mundo en quiebra: su sacrificio individual, su entrega a una causa, son el último desafío a una sociedad indiferente y satisfecha.

En realidad, aunque literatos y activistas practicaban la revolución, sus armas y sus mundos estaban muy alejados. Los anarquistas vivían aquello que los poetas sólo se atrevían a soñar. Mientras los primeros recurrían al atentado o a la acción sindical para alcanzar el cambio social, los segundos hubieran podido hacer suya la frase de Mallarmé: "La vraie bombe, c'est le livre"s; o la de Baroja: "Yo creía, y creo, que la única arma eficaz revolucionaria es el papel impreso"'.

Los intelectuales tomaron del anarquismo formas y rótulos, pero el contenido ideológico apenas les importaba. El poeta era anarquista en la medida en que expresaba de manera individual y nueva su particular visión estética. En tanto que los desposeídos buscaban la completa transformación social y económica, los escritores se pronunciaban por la libertad artística. Para ellos, el anarquismo era estético, rara vez político; las "masas explotadas" no fueron más que el tópico literario de una élite intelectual.

El ambiente cultural de fin de siglo se complica en España con la entrada de las corrientes de pensamiento individualista y nihilista. Los intelectuales y bohemios alternan lecturas de Nietzsche, Schopenhauer, Tolstoi, Stirner, Ibsen, Hauptmann, Strindberg, con las de teóricos ácratas como Bakunin, Kropotkin, Malatesta, Grave, Hamon. En sagaces palabras de un observador poco benévolo, los jóvenes anarquizantes "se tienen por furibundos anarquistas, proclaman la soberanía del «yo», arremeten contra los «viejos moldes», tienen en sus almas de creyentes rebeldías de ateo, sueñan con Ibsen, repiten las frases "profundas» de Nietzsche, adoran a Tolstoi, glorifican a Wagner..." ${ }^{\prime}$ Los mismos literatos confirman este

lisme", Le Mouvement Social, 69 (1969), 21-34; JEAn-Marie Carré, Les écrivains français et le mirage allemand (1800-1940), Paris, 1947; Michel Décaudin, La crise des valeurs symbolistes, Toulouse, 1960; EUgenia K. Herbert, The artist and social reform: France and Belgium 1885-1900, New Haven, 1961; CÉSAR GRAÑA, Bohemian versus Bourgeois: French society and the French man of letters in the nineteenth century, New York, 1964.

- Cit. por Camille Mauclair, Servitude et grandeur litteraires, Paris, 1922, p. 116. En una entrevista con Jules Huret (Écho de Paris, 14.111.1891), Mallarmé afirma que el poeta "est en grève devant la société".

- Pío Baroja, Juventud, egolatria (t. 5 de sus Obras compl.), p. 217.

₹ Nicolás Salmerón, pról. a Degeneración, de Max Nordau, Madrid, 1902, p. 13. La influencia de Nietzsche en la Península ha sido estudiada cuidadosamente por Gonzalo Sobejano, Nietzsche en España, Madrid, 1967. Véase 
juicio. Ya viejo, Azorín recuerda las lecturas de su generación en los años 90: "Nosotros creíamos entonces representada a Europa, principalmente, por Federico Nietzsche [...]. El nombre de Nietzsche hace recordar el de Wagner, otro hombre europeo. Música de Wagner había yo escuchado en Valencia, aplaudida por doctos e indoctos"s. Y Baroja: "Entre los escritores que hoy viven, para mí no hay más que dos verdaderamente geniales, el uno Ibsen, el otro Tolstoi"'.

En 1895, el joven José Martínez Ruiz se entusiasma con un artículo de Édouard Rod sobre la renovación intelectual alemana, influida por Nietzsche, Stirner, Bakunin, y dice, refiriéndose a la influencia de este nuevo pensamiento en España: "La idea anarquista es, ante todo, una protesta y una aspiración; protesta de todas estas arbitrariedades, aspiración hacia un ideal relativamente más humano. Así no tiene programa alguno formulado, ni se atiene a ninguna norma [...]. La anarquía no da ninguna solución ni pretende reformar de un día para otro la actual sociedad"'10. En otras páginas, el futuro Azorín añade a este aspecto ético y humanitario la dimensión estética del anarquismo literario: "la revolución literaria es la vanguardia de la revolución política: el artista es profeta""1.

Martínez Ruiz comparte estos entusiasmos juveniles con otros escritores que se iban dando a conocer por entonces: Maeztu, Baroja, Unamuno. En 1901 escribe este último a Federico Urales: "mi fondo era y es, ante todo, anarquista. Lo que hay es que detesto el sentido sectario y dogmático en que se toma esta denominación $[\ldots]$. El anarquismo de un Ibsen me es simpático, y más

también Udo Rukser, Nietzsche in der Hispania. Ein Beitrag zur hispanischen Kultur-und Geistesgeschichte, Bern, 1962, y el artículo de PAUL ILIE, "Nietzsche in Spain, 1890-1910", PMLA, 79 (1964), 80-96. Sobre su huella en Francia, GENEviève Bianquis, Nietzsche en France. L'influence de Nietzsche sur la pensée française, Paris, 1929 y, más recientemente, J.-M. CARRÉ, op. cit.

8 Azorín, Madrid, en sus Obras compl., t. 6, Madrid, 1962, pp. 245-246. A diferencia de Martínez Ruiz, Federico Urales escribe a la muerte de Nietzsche (La Revista Blanca, Madrid, Suplemento 68, 1.IX.1900, p. 1): "Nietzsche no pudo ser anarquista porque le faltaba el sentimiento de la solidaridad humana".

9 Cit. Por H. Peseux-Righard, "Un romancier espagnol: Pío Baroja", RHi, 23 (1910), p. 117. En Juventud, egolatria, ed. cit., p. 184, Baroja confiesa: "para mí, Tolstoi es un griego: es sereno, claro, sus personajes parecen dioses".

${ }_{10}$ Notas sociales, en el t. 1 de sus Obras compl., Madrid, 1959, pp. 196 y 204. Algo semejante dice Baroja en su discurso de ingreso en la Academia Española (Rapsodias, Obras compl., t. 5, p. 883): "Yo me sentía anarquista, partidario de la resistencia pasiva recomendada por Tolstoi y de la piedad como lector de Schopenhauer y como hombre inclinado al budismo." $\mathrm{Y}$ un párrafo más abajo: "Tampoco cogí del anarquismo su pretendida parte constructiva. Me bastaba su espíritu crítico, medio literario, medio cristiano."

11 Anarquistas literarios, Obras compl., t. 1, p. 165. 
aún el de Kierkegaard, el poderoso pensador danés de quien ante todo se han nutrido Ibsen y Tolstoi. Tolstoi ha sido una de las almas que más hondamente ha sacudido la mía; sus obras han dejado una profunda huella en mi"'12.

No sólo entre los muy jóvenes encontramos estas simpatías. También Alejandro Sawa, Joaquín Dicenta, Eduardo Marquina, Francisco Villaespesa, Manuel del Palacio, Pedro Barrantes, Eduardo Zamacois, entre tantos más, forman parte de esa generación que podríamos llamar, con palabras de Azorín, la de los anarquistas literarios. El auge de este movimiento ocurrió en los años inmediatos al descalabro colonial, pero su vida fue efímera: con la llegada del nuevo siglo, fueron otros los senderos literarios que se ofrecieron a los jóvenes. En el novecientos, mientras los militantes ácratas prefirieron a las explosiones estéticas armas más eficaces en la lucha cotidiana de los asalariados, los escritores e intelectuales optaron por el camino de la pluma y los laureles.

Años más tarde, una revista literaria explicaría esta diferencia fundamental: "Hubo un tiempo en que el ser anarquista, aunque sólo fuera literario, estaba de moda. Eran anarquistas literarios Martínez Ruiz, Ramiro de Maeztu, Manuel Bueno, Julio Camba, Julio Burell, Salvador Canals, López de Ayala... No quedó uno defendiendo las ideas anarquistas y la emancipación humana"'13. En 1902, Federico Urales responde a un artículo anti-anarquista de Maeztu, a quien proclama enfermo de "castración cerebral"14. Dos décadas después, lo recuerda todavía como "nuestro ex amigo y casi nuestro ex compañero", ahora "defensor de los viejos derechos españoles"; menciona sus ideas sobre enseñanza religiosa, y añade: "Ramiro de Maeztu, casi ex anarquista, es el paladín en nuestro país de aquella educación" ${ }^{15}$. La hija de Urales, Federica Montseny, denuncia también a aquel grupo que en un tiempo se presentó como disolvente y ácrata: "Todas las juventudes son revolucionarias y todos los grandes hombres burgueses empezaron por ser demagogos y acabaron siendo académicos. Los nombres de Barrès, de Guerra Junqueiro, de Rochefort, de «Azorín», de tantos otros y tantos otros lo atestiguan" 16 .

¿Entusiasmo juvenil? ¿Simple moda? En 1897, Clarín había in-

12 Reprod. por Federico Urales [Juan Montseny], Evolución de la filosofía en España, ed. crítica de Rafael Pérez de la Dehesa, Barcelona, 1968, t. 2, 29 parte; p. 163.

13 "Nuestros escritores jóvenes", Revista Blanca, Barcelona, Supl. 180 , 15, XI.1980, pp. vi-vii.

1* "La muerte de un superhombre", La Rev. Blanca, Madrid, Supl. 138, 4.1.1902, p. 1.

15 "Comentarios", Rev. Blanca, Barcelona, 15.11.1924.

16 Federica Montseny, "Comentando a un hombre", Rev. Blanca, Barcelona, 15.IV.1929, pp. 15.16. 
tuido lo efímero de esta postura al referirse al autor de Charivari: "Martínez Ruiz es un anarquista literario; y sus doctrinas son terribles; [...] es casi un niño [...]. Pasará el sarampión que acaso es salud y quedará un escritor original, independiente" ${ }_{17}$. Y Luis Nicolau d'Olwer, recordando a la Barcelona del novecientos, escribirá más tarde: "l'anarquisme seguia essent el darrex crit de la moda"18.

Frente al anarquismo literario, intelectual y culto, que busca una estética libre de trabas y la destrucción de los prejuicios y convenciones de una sociedad anquilosada, surge una literatura obrera, desdeñosa de todo refinamiento formal, preocupada por la revolución social y no la artística. José Llunas y Pujais fue quien mejor definió su carácter. En el prólogo a una novela de Anselmo Lorenzo, Llunas explica esta literatura que él llama obrerista: "Podrá faltarle a la literatura obrerista la lucidez de la frase, la brillantez de las figuras, la cadencia de una prosa que despida notas de armonía, los períodos grandilocuentes que más exaltan el sufrimiento que hablan a la razón; mas nada de esto es indispensable para convencer de la bondad de una causa, bastando un regular conocimiento de las principales reglas de Gramática para darse a entender bien a los que no han de juzgar nuestros trabajos literarios por la forma, sino por el fondo; no por la galanura de la frase sino por la intención que la motiva". Lo importante no es inventar nue vas formas o tomar partido por tal o cual corriente estética, sino dejar que entre "como primer factor la exposición y defensa de ideales al calor de los cuales se exponen los sufrimientos de la clase obrera y los remedios que se consideran oportunos para aliviar aquéllos y aun hacerlos desaparecer"; y, por lo tanto, hay que extender el calificativo de literatura obrerista "a todo lo que se escribe desde el punto de vista primordial de exponer los males que aquejan a la clase obrera y manifestar las ideas que a juicio del autor puedan regenerarla"'19.

La prensa anarquista de las últimas décadas del siglo abunda en ejemplos de este tipo de producciones, tanto en prosa como en verso. Es interesante señalar dentro de la poesía obrerista dos corrientes claramente distinguibles: por una parte, la que imita poetas y estilos cultos; por otra, la que recurre a formas tradicionales

1 . Comentario publicado en Madrid Cómico en 1897, cit. por Geoffrey Ribbans, "Riqueza inagotada de las revistas literarias modernas", RLit, 13 (1958), 30-47.

18 Caliu: Records de mestres $i$ amics, México, 1958, p. 45.

19 José Llunas [Y Pujats], "Literatura obrerista", prólogo a Justo Vives, Episodio dramático social, de Anselmo Lorenzo [1" ed., Barcelona, 1893], Buenos Aires, s. a., pp. 10-14. 
y populares, salpicadas a menudo de vulgarismos y de giros lingüísticos regionales, o que incluso está escrita en catalán, valenciano o gallego ${ }^{20}$. En general, tal vez por la escasa cultura literaria de sus autores, la poesía obrerista abunda en formas populares; sin embargo, aunque raras, aparecen aquí y allá parodias y glosas de poetas como Espronceda, Bécquer, Campoamor y Silva. Un autor anónimo ridiculiza el carlismo en estos versos:

Volverán los carlistas incansables nuestros bosques y campos a poblar; y sin trabajo, la comida hecha siempre en ellos tendrán.

Volverán en campañas admirables su fe y su religión a demostrar, apretando a correr cuando los busquen, y cuando no, a robar.

Otra vez en Olot, Cuenca y cien puertos al mundo asombrarán con su piedad afanando, violando, asesinando y después a rezar.

Volverán a gritar jviva don Carlos, y el vino y las Samoggi, y a bailar! y cuando les pregunten-¿quién es ése? dirán: un bruto más.

Volverán a quemar las estaciones y los rails y el telégrafo a cortar, y en los postes, la honra de la patria volverán a colgar.

Volverán las hipócritas beatas corazones de Dios a fabricar, y a más de cuatro tontos de carlistas al campo arrojarán.

Volverán los amables jesuitas en España la guerra a fomentar, a fin de que se diga que sin ellos no es posible la paz.

Volverá, si el Señor no lo remedia, todo esto que he contado y mucho más, pero el placer de darles una tunda jay! también volveráa ${ }^{21}$

20 Llama la atención, en estos años, la abundancia de una literatura anarquista en catalán, valenciano, etc., a diferencia de lo que ocurre en el siglo xx, en el que la producción obrera catalana está redactada casi exclusivamente en castellano. Sería interesante saber si el cambio se debe a una creciente inmigración a Cataluña de obreros castellanos y andaluces o a un rechazo del catalanismo reaccionario de Cambó y la "Lliga".

21 "Becqueriana", en Los Desheredados, Sabadell, 2.XII.1885, p. 3. 
Lo que predomina es la intención ilustrativa y militante. Se trataba de exponer en la literatura anarquista los mismos problemas que se planteaban en los congresos internacionalistas, y de exigir las mismas reivindicaciones que en huelgas y manifestaciones. La desigualdad social, la lucha de clases, la corrupción de las instituciones y del Estado, la injusta distribución de la riqueza, son sólo algunos de los innumerables temas obreros. Lo que el proletariado sostiene y reafirma a través de esta poesía es el rechazo de la sociedad presente y la lucha por un futuro mejor:

Del fondo de la mina, del seno del terruño, venid, hijos del pueblo, venid, regenerad la estólida, decrépita, falaz, artificiosa, hipócrita, egoísta presente sociedad. ...

¡Mirad cómo ya tiemblan los rancios organismos, de vuestro influjo viendo la marea subir! [El tiempo a todos llega! [Salud, hijos del pueblo! ¡Hermanos del trabajo, vuestro es el porvenir!"22

Las prerrogativas, los privilegios basados en la explotación del pueblo deben ser destruidos. Para conquistar la emancipación y establecer la anarquía, el proletariado debe realizar la Revolución Social. Sólo con ella acabarán la esclavitud, la miseria, la injusticia.

[...] No más criminales que con sed impura exploten del hombre su fuerza y saber, y en nombre de un Dios y una patria a su hechura opriman al débil debajo sus pies.

[...] Abajo esas clases, vilmente creadas a sombra y abrigo de la explotación; cantemos, obreros, las nuevas jornadas, que van derramando justicia y amor. Marchemos con amor a la Revolución ${ }^{23}$.

22 Emilio Gante, "Canto al pueblo. (Himno)", en El Corsario, La Coruña, 18.XII.1892, p. 3.

${ }^{23}$ R. C., "La Revolución Social. (Himno)", en La Rezolución Social, Barcelona, 30.XI.1889, p. 4. 
Para los anarquistas, imbuidos de un optimismo absoluto, el éxito de la Revolución es indefectible. Asi lo afirma un anónimo obrero valenciano:

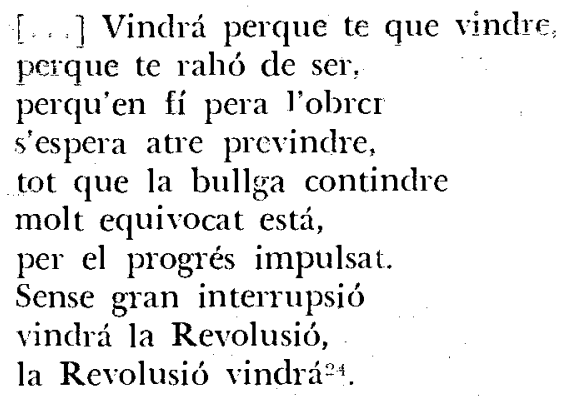

Las diferencias sociales son siempre motivo de rebelión para los grupos proletarios. La burguesía opresora y los trabajadores, eternos explotados, son la constante dicotomía de toda la literatura obrerista. Unos versos catalanes sintetizan con sencillez esta tajante oposición:

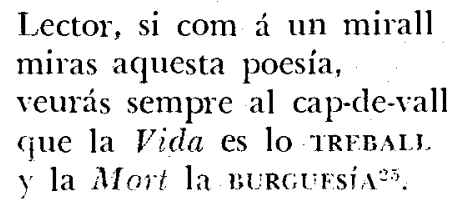

Fn forma más elaborada, este soneto expresa los mismos sentimientos:

Sucumbió un poderoso de la tierra a manos de un oscuro, humilde obrero; conmovióse al saberlo el mundo entero, y el hecho audaz al universo aterra.

Mueren miles de seres en la guerra por la torpe ambición o el vil dinero; lanzólos a luchar monarca fiero... iy nadie se conmueve ni se altera! ¿Qué deducir de aqui? Que la moral del mundo se encuentra pervertida, que el hombre ante los hombres no es igual.

¿Vale más que mil vidas una vida? ¿No es el que mata a muchos criminal? $\mathrm{Si}$ es presidente o rey, no es homicida? 26

24 "La Revolusió vindrá", en El Chornaler, Valencia, 29.XII.1893, p. 3.

25 ABre, "La mort y la vida. (Moraleja)", en La Tramontana, Barcelona, 23.X.1891, p. 3.

20 "Soneto", en El Cosmopolita, Valladolid, 12.X.1901, p. ?. 
En vista de que el Estado es una institución corrompida, creada por unos pocos para oprimir a la mayoría con leyes injustas, los anarquistas establecen su Código penal propio, destinado a castigar los excesos de las clases dominantes. Las medidas ejemplares de ese Código se envuelven en fórmulas sencillas y contundentes:

$$
\begin{aligned}
& \text { Al señor de distinguida } \\
& \text { y elevada posición, } \\
& \text { que vive en lujo y relumbrón } \\
& \text { y sólo ha hecho en su vida } \\
& \text { nada bueno y mucho malo, } \\
& \text { ¡Palo! } \\
& \text { [...] Al cura que a tajo y rajo } \\
& \text { por el campo haciendo mal } \\
& \text { defiende el bien celestial, } \\
& \text { cuatro dedos más abajo } \\
& \text { de donde lleva el bonete, } \\
& \text { ¡Cachete! } \\
& \text { Al cacique que brutal } \\
& \text { acomete a hombres honrados, } \\
& \text { para sacar diputados } \\
& \text { a los que le dan metal } \\
& \text { y otras cosas que yo sé, } \\
& \text { ¡Puntapié! [...] }{ }^{2 i}
\end{aligned}
$$

El proletariado no lucha contra una clase homogénea, sino contra una sociedad compuesta por múltipies intereses e instituciones, entre las cuales se destaca la Iglesia. La religión no sólo ayuda a preservar el statu quo político cuando predica resignación y mansedumbre en este mundo, sino que perpetúa las diferencias sociales al dominar la cultura y la educación. Por eso los anarquistas participan con entusiasmo en el proceso de secularización filosófica y científica de la segunda mitad del siglo, según lo muestra la siguiente glosa de los conocidos versos de Espronceda:

$$
\begin{aligned}
& \text { Las religiones creídas } \\
& \text { por el mundo antiguamente, } \\
& \text { son en el siglo presente } \\
& \text { hojas del árbol caídas. } \\
& \text { Ellas fueron el timón } \\
& \text { del alma y de la conciencia, } \\
& \text { y hoy, en el mar de la ciencia, } \\
& \text { juguetes del viento son. } \\
& \text { Ya corren desvanecidas } \\
& \text { esas hijas del error. }
\end{aligned}
$$

27 "Código penal de El Chornaler", en El Chornaler, 22.II.I884, p. 3. 
¿Qué queda de su esplendor?

¡Las ilusiones perdidas!

Destruyamos sus guaridas

sin que quede ni una en pie,

pues del árbol de la fe

son ¡ay! hojas desprendidas.

Que hoy no acepta la razón

los dogmas desconocidos,

porque son frutos perdidos

del árbol del corazón ${ }^{28}$.

Las nuevas corrientes del pensamiento europeo - Comte, Darwin, Huxley, Taine - contribuyen a intensificar los ataques contra las doctrinas eclesiásticas. Sin embargo, es curioso observar cómo el anarquismo incorpora giros religiosos al pensamiento laico y revolucionario. Esto se manifiesta profusamente en los "credos" y "evangelios" socialistas que se multiplican por entonces, aunque sus antecedentes sean muy anteriores. En efecto, ya en 1812 circulaba este credo patriótico liberal:

Creo en la Junta Suprema de Sevilla, una y poderosa, criadora de la libertad y de la unión, y en Fernando VII su hijo, redentor nuestro, que fue concebido de madre sin cariño, padeció debajo del poder de la infamia, fue tiranizado y vilipendiado, descendió del trono, y al tercer día fue llevado a Francia, y ahora está a la diestra de sus vasallos. Desde allí ha de venir a juzgar a los rebeldes $[\ldots]^{29}$.

En 1870 apareció un "Credo republicano" contra monárquicos y reaccionarios:

Creo en el pueblo todopoderoso, criador de la agricultura, de la industria y del comercio, y en la República, su única hija y próxima señora nuestra; que fue concebida por obra del Sufragio universal,

28 Manuel Quiñones de la Rivera, "Glosa", en El Socialismo, Cádiz, 18.IV.1887, p. 8. Sobre el interés de los anarquistas por la educación y la nueva ciencia, véase mi artículo "Educación anarquista en la España del ochocientos", de próxima aparición en $R O c c$.

29 Biblioteca de la Real Acad. de la Historia, ms. 9/6407, cuya transcripción completa puede verse en Iris M. Zavala, "Las sociedades secretas: prehistoria de los partidos políticos españoles", $B H i, 72$ (1970), 113-147. Hacia fines del siglo abundan en Madrid las "oraciones" dirigidas a figuras populares. Joselito el Gallo y Juan Belmonte fueron objeto de credos y plegarias: "Creo en Belmonte todopoderoso, creador del molinete y de la media verónica..."; "Alabado seas, Joselito, amo y elegancia del toreo... Sé siempre hermano del Calvo Divino, para honra de la fiesta y martirio de los belmontistas. Amén". (Testimonios recogidos por Eugenio Noel en Señoritos chulos..., y citados por Alonso Zamora Vicente, Asedio a "Luces de Bohemia"..., Madrid, 1967, p. 85) . 
nació de la virgen Democracia, padeció bajo el poder de progresistas, unionistas y moderados; fue crucificada, se creyó muerta y sepultada; descendió a las cárceles y pontones, y al poco tiempo resucitó de entre los partidos muertos, subió a las inteligencias y está sentada a la diestra del gobierno del Regente, y desde allí ha de venir a juzgar a los picaros y a dar paz a los pueblos. Creo en el espíritu público, la santa Madre Iglesia libre, la comunión republicana democrática, el perdón de los infelices reaccionarios, la no resurrección de la monarquía perdurable. Amén ${ }^{30}$.

Los anarquistas continúan este género en tono más combativo:

Creo en el hombre, ser poderoso, creador del progreso, base de todos los goces de la tierra, y en la libertad individual, su único medio, móvil nuestro, que fue concebido por obra del humano organismo, nació de la virgen anarquista primitiva, padeció bajo el poder de la religión y del Estado; fue crucificado, muerto y sepultado en las personas de los propagandistas; descendió a los infiernos del Federalismo, y al tercer siglo resucitó de entre los oprimidos, subió a los cielos de los gobiernos mesocráticos, y está sentado a la diestra de la burguesía todopoderosa; desde allí ha de venir a juzgar y extinguir abusos y privilegios; creo en el espíritu del progreso incesante, en la escuela sociológica, reformista-ácrata, en la desaparición de todos los privilegios, en la resurrección de la justicia y en la vida perdurable del bienestar humano, por virtud de mis principios anarquistas. - Amén ${ }^{31}$.

El "Credo de la Mano Negra", hallado en 1883 durante los procesos andaluces, es abiertamente revolucionario:

Creo en el socialismo revolucionario todopoderoso, hijo de la Justicia y de la Anarquía, que es y ha sido perseguido por todos los políticos burgueses, y nació en el seno de la Verdad, padeció bajo el poder de todos los gobiernos, por los que ha sido maltratado y escarnecido y deportado; descendió a los lóbregos calabozos y de ellos ha venido a emancipar el proletariado, y está sentado en el corazón de los asociados. Desde allí juzgará a todos sus enemigos. Creo en los grandes principios de la Anarquía, la Federación y el Colectivismo; creo en la Revolución Social, que ha de redimir a la Humanidad de todos los que hoy la degradan y envilecen. -Amen 32 .

Cuatro años después, El Socialismo, de Cádiz, traduce un "credo judio" escrito por los "compañeros hebreos del East London (barrio donde viven los pobres)":

30 UN Suscritor, "Credo republicano", en la Revista Federal, Madrid, 20.111.1870, p. 110. (Tomado de El Pueblo, de Madrid).

31 Cit. por Gustavo Laiglesia y García, Caracteres del anarquismo en la actualidad, Madrid, 1905, pp. 186-187.

32 Cit. por Laiglesta, ibid., p. 224. 
1. Creo firmemente que todos los hombres nacen libres y que tienen derecho de gozar de libertad toda la vida.

2. Creo firmemente que el hombre que se enriquece con el trabajo ajeno es ladrón.

3. Creo firmemente que la miseria no desaparecerá de la tierra hasta que no se haya organizado el trabajo en común, hasta que no se obligue a cada uno a trabajar según su fuerza y a consumir según sus necesidades.

4. Creo firmemente que el hombre seguirá siendo esclavo mientras permita que uno gobierne a muchos y que unos pocos legislen y hagan leyes para los más.

5. Creo firmemente que la ignorancia prevalecerá sobre el conocimiento, y la oscuridad sobre la luz, mientras que los hombres no se instruyan y eduquen con arreglo a sus capacidades.

6. Creo firmemente que los hombres de una religión perseguirán a los de otras, mientras existan la miseria y la desgracia, y mientras esté la mayoría del género humano, como hoy sucede, afecta de ceguera.

7. Creo firmemente que existirá la guerra y los hombres morirán a millares en el campo de batalla en tanto que prevalezca la fuerza y un país se utilice de la ruina de otro.

8. Creo firmemente que las mujeres no serán más que las esclavas y juguetes de los hombres, mientras que dependan de ellos y no disfruten el producto de su propio trabajo.

9. Creo firmemente que el trabajo, que es el que suministra lo necesario para satisfacer todas las necesidades del hombre, será por todos despreciado mientras que los obreros trabajen para llenar la bolsa de los que no hacen nada.

10. Creo firmemente que los asesinos, ladrones y criminales de todas clases no desaparecerán en tanto los siga engendrando la miseria.

11. Creo firmemente que los hombres se devorarán unos a otros hasta que llegue el día, ya cercano, en que una nueva luz ilumine a la humanidad y los trabajadores se levanten como un solo hombre para arrojar el yugo del capital y confundir a los que los oprimen.

12. Creo firmemente que las inteligencias honradas pueden hacerlo todo; y que el reinado de la razón se halla próximo, haciendo que los hombres vivan como hermanos, y todas las naciones formando una familia.

13. Creo firmemente que el fin de lo presente vendrá pronto y en nuestros días ${ }^{33}$.

Al igual que los credos, los evangelios y los catecismos tenian una larga tradición. Desde principios del siglo habían sido utilizados con propósito didáctico por economistas, historiadores y escri-

${ }^{33}$ "Un credo judío. Los trece artículos de la fe", en El Socialismo, Cádiz, 1.VIII.1887, p. 8 . 
tores como Say, en Francia, y Ackermann, en Inglaterra. En 1865 Bakunin había preparado un Catecismo revolucionario para sus compañeros de la Alianza secreta. En España, el bombástico escritor y político republicano Roque Barcia publicó en 1869 El evangelio del pueblo, de gran éxito entre sus correligionarios ${ }^{34}$. Los anarquistas adoptan la misma forma y, tres años más tarde, Nicolás Alonso Marselau, uno de los internacionalistas andaluces de mayor prestigio, publica desde la cárcel de Sevilla El evangelio del obrero (1872). El folleto anarquista alcanzó amplia difusión y fue aceptado por la Comisión de Propaganda del Consejo de la Federación Sevillana. Años después, La Alarma, de Sevilla, lo reimprimió por entregas con igual fortuna.

El propósito primordial de Marselau es mantener vivo el "dogma de la anarquía" entre los federados españoles. Sus palabras iniciales remedan el incipit de los evangelios de San Mateo y de San Juan:

Libro de la generación del Obrero, hijo del trabajo, de la miseria y las lágrimas. En el principio era la ignorancia; la ignorancia era con el hombre y el hombre era la ignorancia...

Como Cristo, el Obrero soporta persecución e injusticia y sufre tentaciones:

Entonces el Obrero fue llevado a las naciones para ser explotado por sus hermanos.

$\mathrm{Y}$ habiendo ayunado infinidad de siglos, después tuvo hambre.

Y llegándose a él uno de sus hermanos explotadores, le dijo: si tú eres tan poderoso, si en ti reside la riqueza, puesto que, como dices, todo lo produces, di que estas tierras produzcan pan, sin que yo te dé la simiente, sin que te dé un jornal para que te alimentes.

Mas el Obrero respondió: No de solo pan vive el hombre. Yo en verdad tengo en mis manos la riqueza, todo lo produzco, sin mí no habría artes, ni ciencias, ni inventos, todo lo he hecho yo con mi trabajo, pero tú me has robado los instrumentos del trabajo, tú te apoderas del producto de mi sudor, tú me azotas mientras me fatigo, y tienes atadas mis manos para que no me pueda oponer a tus despóticos designios. No vivo sólo de pan, necesito libertad, independencia. Necesito lo que me has robado, y entonces verás cómo de las piedras hago panes, cómo transformo el mundo.

Entonces el explotador lo llevó sobre un alto monte y le mos-

34 También entre los socialistas utópicos franceses florecieron los "evangelios". En 1840, por ejemplo, publicaba Alphonse Esquiros un Evangile du peuple. Cf. David Owen Evans, Le socialisme romantique. Pierre Leroux et ses contemporains, Paris, 1948 (o la versión inglesa de este mismo libro, Oxford Univ. Press, 1951). 
tró todos los reinos del mundo y las glorias de ellos, y le dijo: Todo esto te daré, si cayendo me adorares.

No faltan tampoco las Bienaventuranzas revolucionarias que predica el Obrero:

Felices vosotros, trabajadores y pobres de esta sociedad, porque cesarán vuestras fatigas el día de la Justicia que se acerca [...]. Felices vosotros, : los que ahora lloráis la injusticia social, porque el día llega en que vuestro llanto se convertirá en alegría y la paz reinará en vuestras conciencias, porque no tendréis el remordimiento del haber robado ni explotado a nadie [...]. Felices los que, esclavizados, padecéis por la tiranía y la arbitrariedad de esos que llaman tribunales de justicia. Todas las cadenas han de ser pulverizadas, todos los hierros del esclavo han de ser rotos [...]. Felices cuando os maldijeren y os persiguieren; gozáos y alegráos, porque ésa es una prueba de que no estáis conformes con la explotación existente ${ }^{35}$.

Más de un militante llama la atención sobre el tono y el vocabulario religiosos que suele adoptar esta literatura política: "la caridad cristiana llámase hoy solidaridad; el amor al prójimo, fraternidad humana; no faltan dioses con el nombre de Libertad, Tusticia y Verdad, ni santos que se llamen Angiolillo, Bresci, Caserio, Reclus, etc., siendo el Cristo Redentor la Revolución Social, el demonio causante de nuestros males, "la maldita burguesía», y «el país de la anarquía» el país anhelado; muriéndose hoy, en fin, por la humanidad en lugar de morir por "la causa de Dios" " ${ }_{33}$. Algo semejante dice el peruano González Prada a propósito de los "propagandistas por el hecho": "Acaso yerran; y ¿qué importa? El mérito del sacrificio no estriba en la verdad de la convicción. Los que de buena fe siguieron un error, sacrificándose por la mentira de la patria o por la mentira de la religión; forman hov la pléyade gloriosa de los héroes y los santos. Los grandes vengadores de hoy, ino serán los Cristos de mañana?" ${ }^{37}$ Pero algunos anarquistas manifies-

35 Nicolás Alonso Marselau, El evangelio del obvero, Cárcel de Sevilla. 18.III.1872. pn. 3-10. El opúsculo se reimprimió por entregas en Ia Alarma. Sevilla, 5.XII.1889 y sigs.

36 A. Herrero, "Barriendo escombros", en Anticristo, Algeciras, 31.111.1906, pp. 3-4, y 19.V.1906, pp. 2-3.

37 Manuel González Prada, Anarquía, Barcelona, 1938, p. 113. (La mavoría de estos artículos apareció en Los Parias, Lima, entre 1904 y 1909). Críticos del anarquismo ven con poca simpatía esta tendencia religiosa. En su artículo "Sobre el fulanismo", de 1903, comenta UNAmuno (Ensayos, Madrid. 1951, t. 1, p. 468): "Y es cosa singular aue mientras los anarquistas protestan de ese culto rendido a las personas. multiplican los retratos de Bakunin, de Kropotkin y de otros $y$ han inventado un culto. un verdadero culto, a sus 
tan claramente su irritación ante estas tendencias. Un grupo ácrata, muy influido por Nietzsche, repudia con energía todos los resabios religiosos:

Hoy los anarquistas, así como los cristianos se unen por las ideas de Dios, Patria, Religión, éstos se unen por otras abstracciones no menos vacías de sentido, como "Justicia", "Verdad", "Bienestar Común", "Sacrificio por la Humanidad", resultando que los fantasmas creados por el hombre en la noche de los tiempos no han hecho más que cambiar de nombre y lugar [...]. Un viento castrador corre por entre los anarquistas, segando sus voluntades cual cuchilla de acero, porque al misticismo sucumben o sucumbirán todos los que reemplacen a Dios por la humanidad, sin comprender, sin que puedan concebir sus mentes de que al olvidar al individuo por ésta, al abandonar sus satisfacciones propias por las de los demás, es individuo muerto, colándose de rondón, aunque no lo pretendan, en el cristianismo anarquista ${ }^{38}$.

A medida que la literatura obrerista adquiere palmas y laureles en la prensa del movimiento y en los certámenes anarquistas, aparecen los primeros volúmenes de poesías militantes. En 1885 se publican los "versos socialistas" de Francisco Salazar y Tomás Camacho, reunidos en un tomo titulado $A$ los hijos del pueblo. El libro lleva prólogo de Ernesto Álvarez y una carta del entonces joven Alejandro Sawa, que termina así: "Hace falta, pues, queridos amigos, para que la revolución sea popular, que sea social [...]. El libro $A$ los hijos del pueblo está inspirado en estas ideas, que es preciso que contribuyamos para generalizarlas más, más todavía, a que se disuelvan en la atmósfera de tal modo que así como no hay pulmón que deje de aspirar oxígeno [...], no haya tampoco un cerebro que deje de aspirar socialismo para la formación de la voluntad. Así ganaremos la batalla con menos bajas en nuestro ejército" ${ }^{39}$. La poesía de Salazar y Camacho exalta la lucha del pro-

héroes". "Peldaño", en El Censor, Madrid, 17.IX.1901, p. 2, ataca a los anarquistas para quienes "Czolgosz, como Caserio, como Angiolillo y como tantos otros, es desde hoy un nombre más que ingresa en el santoral del anarquismo [...]. Bruto, si no fue anarquista, presintió el anarquismo: la bandera negra reclama también su nombre; el catecismo de sangre de los libertarios aspira a ser tan extenso como la Biblia".

38 Salvador Rodríguez, en Anticristo, Algeciras, 9.V.1906, p. 1.

39 Alejandro Sawa, "Carta", en $A$ los hijos del pueblo, Versos socialistas, de Francisco Salazar y Tomás Camacho, Madrid, 1885, p. 95. - Sawa (18621909), uno de los personajes más interesantes de fin de siglo, fue figura central en la bohemia madrileña y principal divulgador de la poesía parnasiana francesa. (Cf, el prólogo de Rubén Darío a las póstumas Iluminaciones en la sombra, Madrid, 1910). MaRTínez Ruiz, en 1897 (Charivari, en Obras compl.. t. 1, p. 271), lo ve con poca simpatía: "Alejandro Sawa me parece un fat [...], 
letariado contra "los explotadores", "los autómatas", "la canalla aristocrática", "los padres de la patria", "la propiedad individual", en otros tantos poemas que llevan esos títulos. Según Ernesto Alvarez, con ello se va cumpliendo "un fin humano", que es el "sepelio" de la burguesia, “a fin de que de su putrefacto cadáver surja la nueva y lozana generación, exenta de toda ambición, y donde reinen por modo estable y definitivo la Paz, la Verdad, la Igualdad y la Moral" ${ }^{\prime}$. El libro está dirigido a un público hasta entonces olvidado por los poetas. En una extensa reseña publicada en Ban. dera Social, el comentarista señala que hasta entonces los escritores sólo habían buscado los medios de "aliar el verso con [...] la posición social de los que habían de juzgar y adquirir sus producciones", mientras Salazar y Camacho se han dirigido a otros lectores, al pueblo "que es explotado, que vive en la miseria, que sufre un continuado martirio a que nunca llegaron los adeptos de ninguna idea política, de ninguna religión"; al pueblo que "como no puede pagar inteligencias, fcomo es pobre! no sólo estaba condenado a carecer de ilustración, de pan, de abrigo, sino de cerebros que salieran en defensa de sus derechos" 41 . Estos son los "soldados de la emancipación, hijos de la libertad", "poderosa falange que ha de regenerar al mundo y libertar a la humanidad" 42 . Ellos son los que, lanzándose a la lucha, se oponen a la tiranía de los privilegiados:

La revolución estalla, estalla como la hoguera, como el impetu del bravo que al fin rompe las cadenas con que su opresor le arrastra, como estalla la tormenta...

La revolución estalla cuando el tirano alardea de su poder, y hace al pueblo juguete de sus proezas... $\mathrm{Y}$ jay del tirano aquel día que el pueblo suelte la rienda!

y quiere ser aquí una especie de Jean Moréas". También lo critica Baroja (Juventud, egolatria, ed. cit., p. 210): "Pobre Alejandro. Era en el fondo un hombre sano, un mediterráneo elocuente, nacido para perorar en un país de sol, y se había empeñado en ser un producto podrido del Norte". Manuel Machado, en cambio, le dedicó un lírico "Epitafio": "Jamás hombre más nacido / para el placer, fue al dolor / más derecho. / Jamás ninguno ha caído / con facha de vencedor / tan derecho. / Y es que él se daba a perder / como muchos a ganar. / Y su vida, / por la falta de querer / y sobra de regalar / fue perdida. / Es el morir y olvidar / mejor que amar y vivir. / $Y$ más mérito el dejar / que el conseguir".

40 Ernesto Álvarez, "Prólogo", A los hijos del pueblo, p. x.

\$1 Bandera Social, Madrid, 27.VIII.1886, p. 3.

12 E. Álvarez, "Prólogo" cit., p. viii. 
En vano la tiranía

podrá contener la fuerza

de un pueblo noble que lucha

sacudiendo las cadenas

que le oprimen, porque entonces,

rompiendo la valla inmensa

de la tiranía, y ciego

de su indignación extrema,

tal vez reduzca a ceniza

al tirano y su bandera ${ }^{43}$.

Diez años después de publicada la primera edición de este volumen de versos dirigidos $A$ los hijos del pueblo, una militante anarquista, Ana María M..., daba a conocer sus poemas feministas $A$ las hijas del pueblot.

\section{II}

Los temas de la prensa obrera revolucionaria influyen decisivamente en la poesía social cultivada por los anarquistas literarios. Escritores como Pedro Barrantes, Joaquín Dicenta, Manuel del Palacio, entre muchos otros, plantean temas semejantes a los de sus colegas proletarios. Así, José Alcalá Galiano critica, en "El mendrugo", la falta de caridad y la indiferencia social:

Roto, sucio, raquítico y hambriento, enfermo, y sin trabajo en su cojera, mirad a ese mendigo macilento subir con gran dolor una escalera.

Llama a una puerta; la criada le da, después de no pequeño rato, una miga de pan fosilizada y un mendrugo más duro que un zapato.

Al tomarlo, con hondo desconsuelo exclama, y con escéptica ironía:

“¡Padre nuestro! si estás allá en el cielo, ¿esto se llama el pan de cada día?" 45

43 F. Salazar y T. Camacho, A los hijos del pueblo, pp. 62-63.

i* Otra curiosa colección de poesías es la de José MARía BLázQLez de PEDRo, Rebeldias cantadas (Librería Satanás, Madrid, 1905), compuesta desde la que él llama "Cárcel ¿Modelo? de Madrid" para divulgar "el ideal amado" y atacar a los "subhombres que se inferiorizan, deshumanan e injurian a sí propios con el mote de autoridades" (p. 16). En 1889 se había impreso un largo poema antirreligioso de $\mathrm{M}$ [IGUeL] $\mathrm{R}$ [EY], ¿Dónde está Dios?, y hacia la misma época José Llunas y Pujals publicó una extensa poesía en tres cantos, La Revolución, Barcelona, 188...

45 José Alcalá Galiano, "El mendrugo", en La Revista Social, Barcelona, 
La deshumanización de la sociedad es, para todos estos autores, responsable de que el pueblo recurra al robo o al asesinato para remediar su penuria. Los estudios sociológicos y jurídicos de boga influyen en los jóvenes intelectuales españoles. Martínez Ruiz, gran admirador de Pedro Dorado Montero, traduce Las prisiones, de Kropotkin, y publica en 1899 un extenso estudio de sociología criminal, donde traza la historia de las diversas doctrinas europeas sobre ese tema ${ }^{46}$, polemizando con Cesare Lombroso y Enrico Ferri y tomando partido por Dorado, Gabriel Tarde, Emile Girardin, Kropotkin y Augustin Hamon, criminalistas que, en mayor o menor grado, ven en la sociedad la verdadera causa del delito.

Estas nociones, parte del clima intelectual de la época, están implícitas en el soneto "Rèo de muerte", de Francisco Rodríguez Marín. El malhechor, víctima de sus circunstancias sociales -la miseria y la soledad-, no podrá encontrar esperanza sino en la muerte:

En tugurio misérrimo naciste, engendro de vicioso maridaje; dejáronte crecer como salvaje; de nadie amor ni amparo mereciste.

Solo, desharrapado, hambriento y triste quemó tus venas el social ultraje, y, lanzado a la vida del pillaje, crímenes espantosos cometiste.

La sociedad te asió con mano fuerte, al fin en ti ha pensado, y te condena a la pena más grave: a la de muerte.

19.IV.1878, p. 4. En 1872 había publicado Alcalá su Estereoscopio social, con prólogo de Galdós, y el 27.IV.1895 La Idea Libre, de Madrid, reprodujo otro de sus poemas sociales, "La soirée. (Pintura al petróleo)". De él dice Rubév Darío, España contemporánea, p. 220: "es otro hijo de su padre. Ha traducido a Byron en verso. Ignoro si el sacrificio fue antes o después de entrar en la Academia".

${ }^{46}$ Obras compl., t. I, pp. 441-574 (con prólogo de Francisco Pi y Margall) . "Teórico y propagandista" del anarquismo lo llama E. INMAN Fox, "Tosé Martínez Ruiz. Sobre el anarquismo del futuro Azorín", ROcc, 12 (1966), p. I60. rCf. también, del mismo estudioso, "Una bibliografía anotada del periodismo de José Martínez Ruiz (Azorín) : 1894-1904", RLit, 28 (1965), 231-244, y su "Introducción biográfica y crítica" a $L a$ voluntad, Madrid, 1968]. Resulta difícil coincidir plenamente con este modo de ver. Más justo y equilibrado me parece considerar al joven Azorín como uno de los varios escritores de fin de siglo que se declararon en rebelión contra la sociedad burguesa y la estética anquilosada de la Regencia. Todos ellos tomaron prestados rótulos y actitudes del anarquismo, subrayando lo que éste tiene de individualista, renovador, iconoclasta e, incluso, humanitario, pero dejando de lado los programas económicos y sociales del anarquismo militante, el único que tiene verdaderas raíces populares en España. 
¡Muere, muere con ánima serena, y bendice con júbilo tu suerte, porque pena que es última no es penal $4 \tau$

El desencanto con la sociedad es común a gran parte de los autores de fin de siglo. Sin embargo, mientras los anarquistas afirman que el cambio sólo puede venir de la Revolución Social, los escritores anarquizantes piensan casi exclusivamente en términos nihilistas: subrayan el potencial destructivo del proletariado, pero hacen caso omiso de las premisas del socialismo, orientado a la creación de un mundo nuevo. Joaquín Dicenta, en "El andamio", nos muestra a un albañil capaz de destruir no sólo la morada del burgués, sino todo el edificio social:

$\lceil\ldots\rceil$ Tal vez llegue a pensar que en la morada donde dejó pedazos de su vida, por él, piedra tras piedra levantada, por él, golpe tras golpe construida, habitará el burgués, el caballero que tiene por insulto y por ultraje el que roce la blusa del obrero el satinado paño de su traje.

Tal vez lo piensa, y al pensarlo cante haciendo del cantar grito de guerra, y queriendo decir con arrogante voz a los poderosos de la tierra: "Desde esta humilde tabla os desafío; miradme bien, vuestró edificio es mío; mío desde el remate hasta la planta, mío porque mi mano lo construye, y esta mano es la mano que levanta, pero es también la mano que destruye ${ }^{48}$.

47 F. Rodrí́cuez Marín, "Reo de muerte", en La Idea Libre, Madrid, 6.VII.I895, p. 2.

"8 Joaquín Dicenta, "El andamio", en Don Quijote, Madrid, 3.IX.1897, y en La Idea Libre, Madrid, 3.VI.1899. p. 2. Lurs Bonaroux dice en su "Prólogo" a Spoliarum, 2" ed., Madrid, 1891, que su autor, Dicenta, "forma en las filas de la vanguardia de revolucionarios que son primero niños sublimes que no miran el ayer ni se preocupan del mañana; después, jóvenes genero sos que derrochan el talento como derrochan la vida, y en fin, combatientes aguerridos que, polvorientos y sangrando, marchan a buen paso hacia la montaña del ideal, dejando atrás el pasado y diciendo: ‘Mueral" (p. 8). Y Anselio Lorenzo, en su reseña de Juan José, en La Idea Libre, Madrid, $30 . X I .1895$, p. 2: "no es tan "echao pa'alante" como exige la crítica anarquista". Unamuno, en "Sobre la tumba de Costa" (Obras completas, t. 3, Madrid, 1958, p. 1135), observa que Dicenta "por haber escrito su vigorosisimo Juan José [...] se creyó socialista". 
El desastre de 1898 produjo una violenta impresión en los intelectuales, testigos de la ruina española. Pedro Barrantes, abandonando el tono religioso de algunas de sus primeras poesías de Tierra $y$ cielo (Madrid, 1896), publica en 1900 un extenso poema a la bandera roja que guiará a España a una nueva vida:

$[\ldots]$ ¡Estandarte de luz que allí en el alma

flota gentil de la ilusión al viento!

iTú solo puedes devolver la calma

a esta nación vencida y sin aliento!

iTú solo puedes despertar en ella

las grandes y viriles energías

que destruyeron con su torpe huella

las inquisitoriales monarquías!

Bajo tu pabellón inmaculado

justicia y libertad tienen su cuna.

Por eso el corazón te ha consagrado

pasión más entusiasta que ninguna.

¡Bandera roja! ¡Salve! En lontananza,

serena y bella palpitar te veo

al ósculo de amor de la esperanza,

con la infinita fiebre del deseo $[\ldots]^{49}$.

El anarquismo literario fue el resultado efímero del descontento artístico y espiritual de un grupo de escritores de fin de siglo, que veían en el rechazo de los viejos moldes estéticos y sociales un medio eficaz para la regeneración de una España - y una Europaen decadencia ${ }^{30}$. La anarquía política y la intelectual fueron dos aspectos del múltiple descontento español en los años de la Regencia. Lo que los militantes ácratas habían logrado en el plano político lo iban a lograr los literatos jóvenes en su asalto a una estética acartonada. Si se echa una rápida ojeada a las revistas literarias y culturales en que publicaban los escritores disconformes, se observa de inmediato el hecho significativo de que todas ellas comparten

49 PEDro Barrantes, "La bandera roja", en Don Quijote, Madrid, 16.111. 1900 , p. 1. En el mismo tono escribió también "Bandera negra", que dedicó a Rubén Darío. Su Delirium tremens revela el tono y la intención de la nueva estética.

50 Sobre los escritores de la Regencia y el Desastre véase el excelente libro de Luis S. Granjel, La generación literaria del 98, Salamanca, 1966. También José MARÍA DE Cossío, Cincuenta años de poesía española (1850-1900), Madrid, 1960, t. 2, y Gulllermo DíAz-Plaja, Modernismo frente a noventa y ocho, Madrid, 1951. Son interesantes las diferencias entre la joven genera. ción de la última década del xix y la de la Primera Guerra Mundial. Mientras aquélla tuvo fugaces veleidades anarquistas, los intelectuales de 1914 -Julián Besteiro, Fernando de los Ríos, Luis Araquistáin- fueron directamente al socialismo, en el cual militaron. 
en mayor o menor medida la preocupación por una España nueva ${ }^{51}$. Eduardo Zamacois explica en el primer número de Germinal: “¿Reverdecerán sus laureles? ¿Tornará a ser lo que fue? ¿No tendrá este triste ocaso un próximo y risueño amanecer?... Sí; a España aún le aguarda un glorioso germinal; España no está muerta...: está dormida" "s? Y Y uno de los "propósitos" que formula Vida Nueva es luchar por una estética libre y renovadora: "Ideas, reformas, leyes nuevas, organización nueva, eso es lo que importa [...]. Venimos a propagar y a defender lo nuevo, lo que el público ansia, lo moderno, lo que en toda Europa es corriente y aquí no llega por miedo a la rutina y tiranía de la costumbre [...]. Vida Nueva será no el periódico de hoy, sino el periódico de mañana" "s3.

Después del Desastre, otros grupos compartieron el j'accuse de los intelectuales exaltados, y la preocupación por la regeneración de España fue tópico de derechas e izquierdas. El anarquismo literario muere en medio del torbellino del siglo que empieza, mientras los escritores sueñan en un nuevo renacer, olvidados de nihilismos y destrucciones.

En tanto que el movimiento anarquista seguía atrayendo adeptos y su producción literaria cosechaba aplausos de militantes y correligionarios, el arte social culto daba paso a nuevas formas de expresión. Si el anarquismo literario fue una etapa transitoria de la estética de fin de siglo, la literatura obrerista siguió siendo el arma de difusión ideológica y cultural del movimiento anarquista español hasta los años de la Guerra Civil.

Wesleyan University.

Clara E. Lidda

\footnotetext{
51 Para un estudio de las revistas literarias de fin de siglo véanse L. S. Granjel, op. cit., pp. 99-124, y Biografia de "Revista Nueva" (1899), Salamanca, 1962; G. Díaz-Plaja, op. cit., pp. 29 ss.; G. Ribbans, art. cit.; DoMingo Paniagua, Revistas culturales contemporáneas, I. De "Germinal" a "Prometeo", Madrid, 1964; Germán Bleiberg, "Algunas revistas literarias hacia 1898", $A r b, 11$ (1948), 465-480; GuIllermo DE Torre, "La generación española de 1898 en las revistas de su tiempo", Nosotros, 15 (1941), 3-38; y Antonio Espina, El cuarto poder, Madrid, 1960.

32 Eduardo Zamacois, en Germinal, Madrid, núm. 1 (30.IV.1897), p. 1.

53 "Propósitos", Vida Nueva, Madrid, 12.VI.1898, p. 1.
} 